\title{
Analisis Kepuasan Pengguna Aplikasi KAI Access Sebagai Media Pemesanan Tiket Kereta Api Menggunakan Metode EUCS
}

\author{
User Satisfaction Analysis of the KAI Access Application as a Train Ticket Booking \\ Media Using the EUCS Method
}

\author{
Hendrik Setiawan ${ }^{1}$, Dien Novita ${ }^{2}$ \\ ${ }^{1,2}$ Program Studi Sistem Informasi, Universitas Multi Data Palembang \\ E-mail: ${ }^{1}$ hendriksetiawan1198@mhs.mdp.ac.id, ${ }^{2}$ dien@ mdp.ac.id
}

\begin{abstract}
Abstrak
KAI Access merupakan aplikasi yang resmi dari PT KAI, dan dirilis untuk memenuhi kebutuhan penumpang baik kereta api jarak jauh, menengah, maupun lokal/komuter. Tujuan penelitian ini adalah untuk mengetahui apakah terdapat pengaruh dari content, accurancy, format, ease of use dan timeliness terhadap kepuasan pengguna aplikasi KAI Access dan untuk mengetahuinya apakah terdapat pengaruh tingkat kepuasan pengguna aplikasi KAI Access sebagai media pemesanan tiket kereta api. Metode yang digunakan dalam penelitian ini adalah End User Computing Satisfaction (EUCS) yang terdiri dari lima faktor, yaitu: isi (content), ketepatan (accuracy), bentuk (format), kemudahan penggunaan (ease of use), dan ketepatan waktu (timeliness). Proses pengumpulan data dilakukan dengan melakukan penyebaran kuesioner kepada masyarakat yang menggunakan aplikasi KAI Access di Palembang. Teknik pengambilan sampel menggunakan random sampling. Metode pengolahan data yang dilakukan dalam penelitian ini menggunakan uji validitas, uji reliabilitas, dan uji hipotesis yang diolah dengan menggunakan software SPSS. Hasil Pengujian hipotesis terdapat 3 variabel yang berpengaruh yaitu accuracy, format, timeliness dan terdapat 2 variabel yang tidak berpengaruh yaitu content dan ease of use. Berdasarkan analisis korelasi diperoleh $\mathrm{R}^{2}$ sebesar 0,679 menunjukan bahwa variabel satisfaction dapat dijelaskan oleh variabel content, accuracy, format, ease of use dan timeliness sebesar $67,9 \%$.
\end{abstract}

Kata kunci: kepuasan, pengguna, KAI Access, EUCS, SPSS

\begin{abstract}
KAI Access is an official application from PT KAI and was released to meet the needs of passengers both long, medium, and local trains/commuters. The purpose of this research is to find out if there is an influence of content, accuracy, format, ease of use and timeliness on the satisfaction of KAI Access app users and to find out if there is an influence on the level of user satisfaction of KAI Access application as a media of booking train tickets. The method used in this study is End User Computing Satisfaction (EUCS) which consists of five factors, they are content, accuracy, format, ease of use, dan timeliness. The data collection process is carried out by disseminating questionnaires to people using the KAI Access app in Palembang. Sampling techniques using random sampling. The data processing method conducted in this study uses validity test, reliability test, and hypothesis test processed using software SPSS. The results of this research were from 100 respondents, 68 respondents who were satisfied with KAI Access. Hypothesis test results: 3 variables affect are accuracy, format, timeliness, and 2 variables do not affect: content and ease of use. Based on the correlation analysis obtained $R^{2}$ of 0.679 shows that the satisfaction variable can be explained by the variables content, accuracy, format, ease of use and timeliness of $67.9 \%$.
\end{abstract}

Keywords: satisfaction, users, KAI Access, EUCS, SPSS 


\section{PENDAHULUAN}

Di zaman globalisasi, digital, dan modern saat ini segala sesuatu dituntut agar lebih cepat, waktu menjadi sesuatu yang sangat mahal di era ini, sehingga setiap masyarakat sangat memperhatikan semuannya yang berhubungan dengan waktu. Dimana itu dimaksudkan bahwa transportasi sebagai alat bantu yang dipakai untuk proses pindah harus sesuai dan cocok dengan jarak, objek dan maksud objek, baik dari sisi kuantitasnya maupun sisi kualitasnya [1]. Sebagaimana yang telah dikemukakan, transportasi juga diartikan sebagai alat. Alat tertentu yang dapat keterkaitannya dengan suatu proses bisnis layanan. Globalisasi bisnis jasa saat ini semakin berkembang pesat, diantarannya adalah jasa transportasi. Hal ini berakibat pada semakin naiknya tingkat persaingan antar perusahaan layanan transportasi. saat ini konsumen lebih memilih layanan transportasi secara selektif. Dengan berkembangnya bisnis layanan transportasi membawa konsekuensi semakin diperhatikannya service quality.

Perusahaan Kereta Api Indonesia (KAI) adalah satu-satunya perusahaan BUMN milik pemerintah dibawah dinas perhubungan yang bergerak dibidang perkereta apian, setiap perusahannya terletak dipulau Jawa maupun di pulau Sumatera. Mengingat peningkatan kegiatan masyarakat dan kompetensi bisnis pada jasa transportasi darat, setelah berinovasi PT KAI akhirnya mempunyai salah satu aplikasi superior yaitu Aplikasi KAI Access.

Kereta api nampaknya menjadi salah satu alat transportasi favorit orang Indonesia terbukti dengan meningkatnya layanan khusus Kereta Api Indonesia di berbagai perangkat Android, IOS, dan Windows Phone. Beberapa aplikasi ini seperti Treveloka, Tiket.com, Pegipegi, Tokopedia, dan juga aplikasi favorit yang akan kita bahas yaitu KAI Access. Hal ini yang menjadi salah satu faktor yang ingin dijadikan pedoman oleh peneliti untuk mempelajari lebih lanjut tentang KAI Access terhadap kepuasan para pengguna aplikasi transportasi darat tersebut. Saat ini telah muncul bermacam-macam jenis dari aplikasi mobile yang ada, salah satunya adalah mobile ticketting. Mobile ticketting merupakan aplikasi mobile yang juga dapat digunakan untuk pemesanan serta pembelian tiket [2].

Aspek penting yang harus diperhatikan dalam pengembangan aplikasi ini adalah persepsi pengguna. Ketika pengguna puas dengan suatu aplikasi maka pengguna akan terus menggunakan aplikasi tersebut. Evaluasi penggalaman pengguna pada suatu aplikasi dibutuhkan agar dapat melihat kekurangan dari sistemnya, sehingga dapat terus mengembangkan sistem sesuai dengan kebutuhan pengguna [3].

Penelitian ini fokus terhadap kepuasan pengguna aplikasi KAI Access, menunjukan bahwa kualitas layanan penting untuk diperhatikan dianggap sebagai strategi bisnis yang bertujuan untuk memenuhi kepercayaan pengguna terhadap pelayanan yang diterima, keinginan serta kebutuhan sehingga menimbulkan pengaruh positif yaitu loyalitas pelanggan secara terus menerus. Alasan mengambil judul ini dikarenakan penelitian ini masih sedikitnya diteliti oleh orang lain serta ada hal yang dipertimbangkan dalam penelitian ini seperti bagaimana minat pengguna KAI Access, masalah apa yang terdapat dari segi isi aplikasi, ketepatan sistem dalam menghasilkan output, apakah tampilan sistem sudah cukup baik, apakah sistem mudah untuk digunakan, bagaimana kecepatan output sistem. Hal tersebut yang menjadikan alasan peneliti dalam menggambil objek penelitian KAI Access dalam mengatasi permasalahan dalam hal kepuasan pelanggan.

Penelitian ini bertujuan untuk menganalisis kepuasan pengguna aplikasi KAI Access sebagai media pemesanan tiket kereta api secara online dengan menggunakan metode End User Computing Satisfaction atau disingkat EUCS. End User Computing Satisfaction (EUCS) adalah metode untuk mengukur tingkat kepuasan pengguna sistem aplikasi dengan membandingkan antara harapan dan kenyataan dari sebuah sistem informasi.

Definisi EUCS dari sebuah sistem informasi adalah evaluasi keseluruhan penggunaan sistem informasi berdasarkan pengalaman pengguna dalam menggunakan sistem. Model EUCS ini dikembangkan oleh [4] dimana keduanya menekankan kepuasan (satisfaction) pengguna akhir dari aspek teknologi. Penilaian kepuasan tersebut diamati dari lima buah dimensi yaitu, isi 
(content), keakuratan (accuracy), bentuk (format), kemudahan penggunaan (ease of use), dan ketepatan waktu (timeliness) [4].

\section{METODE PENELITIAN}

\subsection{Tahapan Penelitian}

Gambar 1 berikut merupakan tahapan penelitian yang dilakukan dalam penelitian ini:

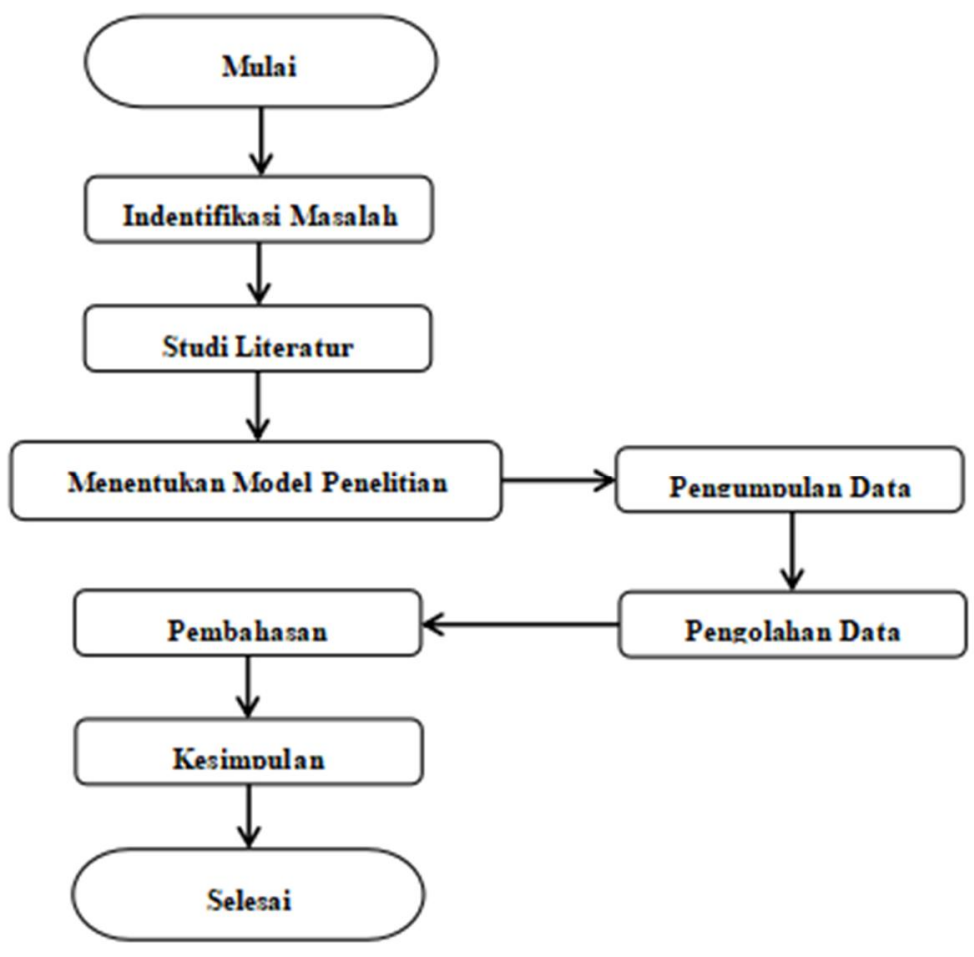

Gambar 1. Tahap Penelitian

Langkah awal penelitian yaitu penulis mengidentifikasi masalah berdasarkan latar belakang yang dibuat berdasarkan analisis terhadap peneltian-penelitian sebelumnya dan kondisi perkembangan teknologi sekarang ini khususnya terkait kepuasan pengguna [5]. Langkah berikutnya yaitu studi literatur mencari referensi dan mengumpulkan teori apa saja yang akan di gunakan pada penelitian ini. Menentukan model penelitian, pada tahap ini menentukan model yang digunakan untuk melakukan penelitian, model yang cocok digunakan pada penelitian mengukur kepuasan pengguna ini adalah End User Computing Satisfaction [6]. Selanjutnya pengolahan data pada tahap ini melakukan pengolahan data yang di dapat dari kuesioner dan menggunakan aplikasi SPSS untuk mengolah datanya. Hasil dari data yang telah diolah, selanjutnya dijelaskan hasilnya berdasarkan rumusan hipotesis dari permasalahan dan pengujian yang telah dilakukan. Terakhir membentuk kesimpulan dari hasil penelitian yang telah dilakukan.

\subsection{Populasi dan Sampel}

Populasi dalam penelitian ini adalah masyarakat pengguna aplikasi KAI Access yang jumlahnya tidak diketahui dan dapat dikatakan dalam kategori tidak terhingga. Sampel adalah bagian dari jumlah dan karakteristik yang dimiliki populasi. Bila populasi besar, dan tidak mungkin mempelajari semua yang ada pada populasi, misalnya karena keterbatasan waktu, tenaga, dan dana, maka dapat menggunakan sampel yang diambil dari populasi itu [7]. Apa 
yang dipelajari dari sampel itu, kesimpulannya akan dapat diberlakukan untuk populasi. Untuk itu sampel yang diambil dari populasi harus betul-betul representative atau mewakili.

\subsection{Penentuan Sampel}

Dalam menentukan jumlah sampel yang akan digunakan dalam penelitian ini, dihitung menggunakan rumus Paul Leedy [8]. (e) = sebesar $10 \%$ dan tingkat keyakinan sebesar $95 \%$ $(\mathrm{Z}=1,96)$.

$$
\begin{aligned}
& n=\left(\frac{Z}{e}\right)^{2} p(1-p) \\
& n=\left(\frac{1,96}{0,1}\right)^{2} 0,5(1-0,5) \\
& n=96,04
\end{aligned}
$$

Tingkat kesalahan (e) yang dapat ditoleransi pada penelitian ini ditetapkan sebesar $10 \%$ dan tingkat keyakinan dalam penentuan sampel yang digunakan adalah $95 \%$ atau $Z=1,96$. Nilai tingkat keyakinan $95 \%$ atau $\mathrm{Z}=1,96$ adalah tingkat keyakinan yang paling sering digunakan. Tingkat keyakinan $95 \%$ atau $\mathrm{Z}=1,96$ memberikan keseimbangan antara presisi dan reliabilitas. Jumlah anggota populasi dalam penelitian ini tidak diketahui, maka nilai $\mathrm{P}$ maksimal adalah 0,5. Berpedoman hasil perhitungan tersebut maka jumlah responden dibulatkan sebanyak 100 responden.

\subsection{Variabel Penelitian}

Berdasarkan studi literatur, diperoleh variabel dan indikator yang digunakan dalam

\begin{tabular}{|c|c|c|c|}
\hline Variabel & Kode & Indikator & Sumber \\
\hline \multirow{4}{*}{ Content (X1) } & $\mathrm{C} 1$ & $\begin{array}{l}\text { Informasi yang dihasilkan } \\
\text { sesuai. }\end{array}$ & \multirow{2}{*}{ [4], [9], [10] } \\
\hline & $\mathrm{C} 2$ & Mudah dipahami dan jelas. & \\
\hline & $\mathrm{C} 3$ & Kelengkapan Informasi. & \\
\hline & $\mathrm{C} 4$ & Kemudahan & [4], [9], [10] \\
\hline \multirow{4}{*}{ Accuracy (X2) } & A1 & $\begin{array}{l}\text { Informasi yang dihasilkan } \\
\text { benar }\end{array}$ & [4], [9], [10] \\
\hline & A2 & $\begin{array}{l}\text { Keluaran yang dihasilkan } \\
\text { selalu akurat. }\end{array}$ & [4], [9] \\
\hline & $\mathrm{A} 3$ & Jarang terjadi error atau bug & \multirow{2}{*}{ [4], [9], [10], [11] } \\
\hline & A4 & Kehandalan & \\
\hline \multirow{4}{*}{ Format (X3) } & F1 & $\begin{array}{l}\text { Kemudahan Penggunaan } \\
\text { User Interface. }\end{array}$ & [10] \\
\hline & $\mathrm{F} 2$ & $\begin{array}{l}\text { Memiliki User Interface } \\
\text { yang menarik. }\end{array}$ & [11] \\
\hline & F3 & $\begin{array}{l}\text { Output yang ditampilkan } \\
\text { aplikasi memilki kualitas } \\
\text { yang baik. }\end{array}$ & \multirow[t]{2}{*}{ [4], [9], [10] } \\
\hline & $\mathrm{F} 4$ & Kejelasan & \\
\hline \multirow{3}{*}{$\begin{array}{l}\text { Ease of Use } \\
\quad(\mathrm{X} 4)\end{array}$} & E1 & $\begin{array}{l}\text { Kemudahan dalam } \\
\text { penggunaan }\end{array}$ & {$[4],[9],[10],[11]$} \\
\hline & E2 & Mudah diakses. & [10] \\
\hline & E3 & Mudah dipelajari/dipahami & [4], [9], [10] \\
\hline
\end{tabular}
penelitian ini merujuk pada jurnal penelitian sebelumnya seperti pada Tabel 1 yaitu variabel dan indikator penelitian metode EUCS. 


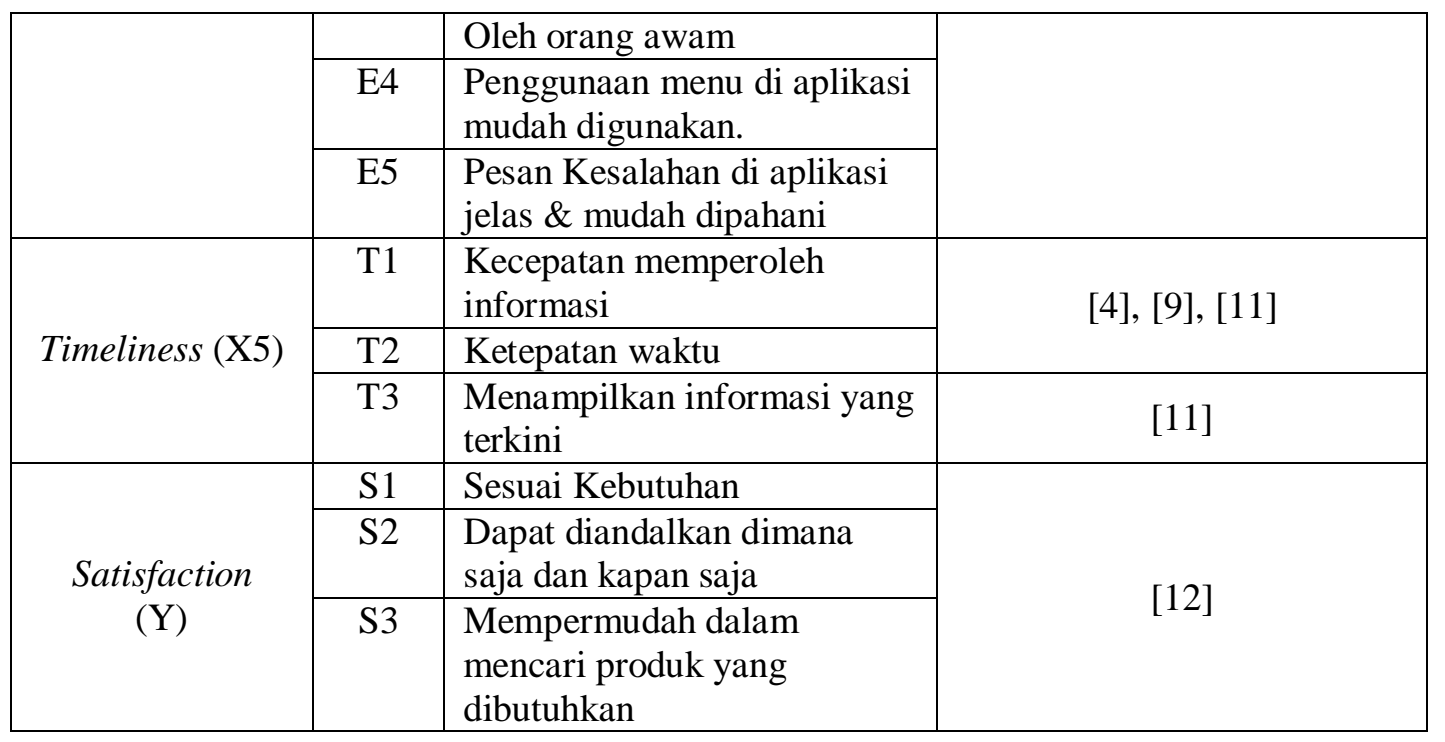

Berdasarkan studi literatur, diperoleh juga variabel dan indikator yang digunakan penelitian merujuk pada jurnal penelitian sebelumnya mengenai penelitian metode EUCS.

\subsection{Hipotesis Penelitian}

Penelitian ini menggunakan desain kausal yang bertujuan untuk menganalisis hubungan antara satu variabel dengan variabel lainnya [13]. Berdasarkan permasalahan yang ada maka disusun hipotesis seperti Gambar 2 berikut.

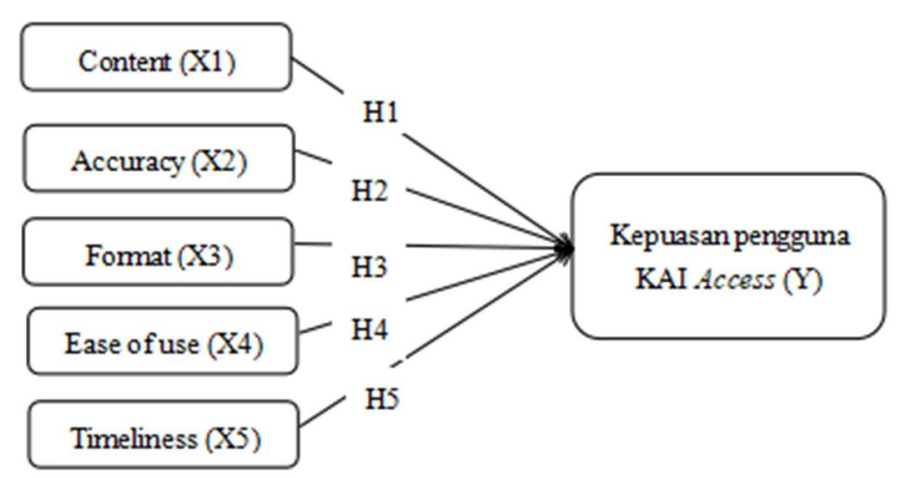

Gambar 2. Hipotesis Penelitian

Berikut adalah hipotesis penelitian berdasarkan model EUCS yang memiliki 5 hipotesis yaitu:

$\mathrm{H} 1=$ Variabel content $(\mathrm{X} 1)$ berpengaruh terhadap tingkat kepuasan pengguna $(\mathrm{Y})$ aplikasi KAI Access.

$\mathrm{H} 2=$ Variabel accuracy $(\mathrm{X} 2)$ berpengaruh terhadap tingkat kepuasan pengguna $(\mathrm{Y})$ aplikasi KAI Access.

$\mathrm{H} 3=$ Variabel format (X3) berpengaruh terhadap tingkat kepuasan pengguna (Y) aplikasi KAI Access.

$\mathrm{H} 4=$ Variabel ease of use (X4) berpengaruh terhadap tingkat kepuasan pengguna $(\mathrm{Y})$ aplikasi KAI Access.

$\mathrm{H} 5=$ Variabel timeliness $(\mathrm{X} 5)$ berpengaruh terhadap tingkat kepuasan pengguna $(\mathrm{Y})$ aplikasi KAI Access. 


\section{HASIL DAN PEMBAHASAN}

\subsection{Profil Responden}

Data responden dikelompokan berdasarkan jenis kelamin, usia, pendidikan terakhir, pekerjaan, dan jumlah transaksi. Gambar 3 adalah responden berdasarkan jenis kelamin.

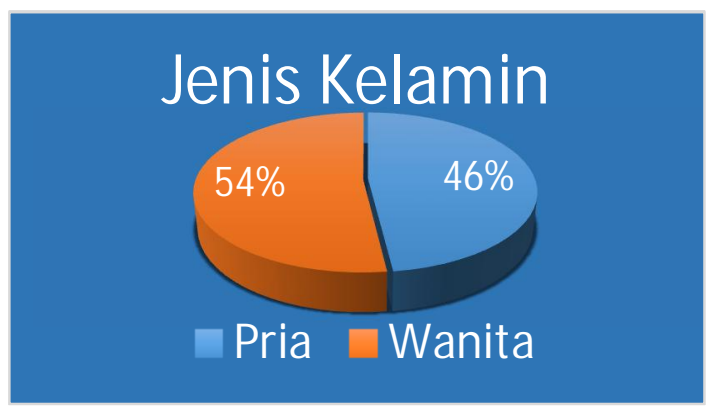

Gambar 3. Jenis Kelamin

Dari Gambar 3 menunjukan bahwa dari 100 data responden yang digunakan dalam penelitian ini, paling banyak didominasi oleh responden berjenis kelamin wanita berjumlah 54 orang dengan persentase 54\%, sedangkan berjenis kelamin pria berjumlah 46 orang dengan persentase $46 \%$. Gambar 4 adalah data responden berdasarkan usia.

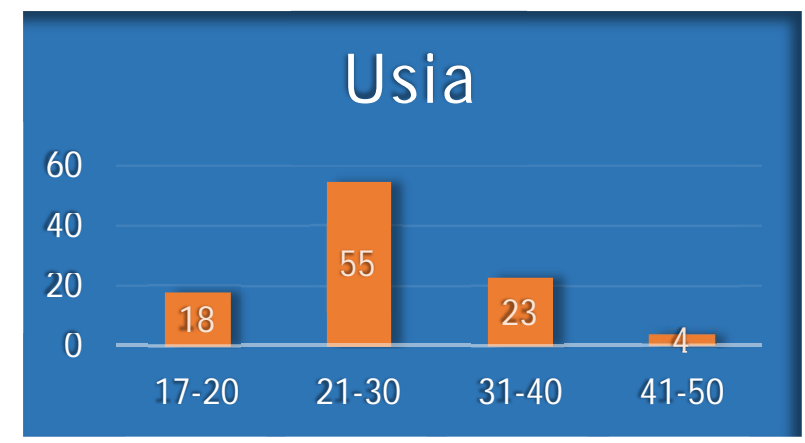

Gambar 4. Usia

Dari Gambar 4 menunjukan bahwa dari 100 data responden yang digunakan dalam penelitian ini, paling banyak didominisasi oleh responden dengan rentang usia 21-30 tahun berjumlah 55 orang dengan persentase 55\%, lalu untuk usia 31-40 tahun berjumlah 23 orang dengan persentase $23 \%$, kemudian usia 17-20 tahun berjumlah 18 orang dengan persentase $18 \%$ dan 41-50 tahun berjumlah 4 orang dengan persentase $4 \%$. Gambar 5 adalah data responden berdasarkan pendidikan terakhir. 


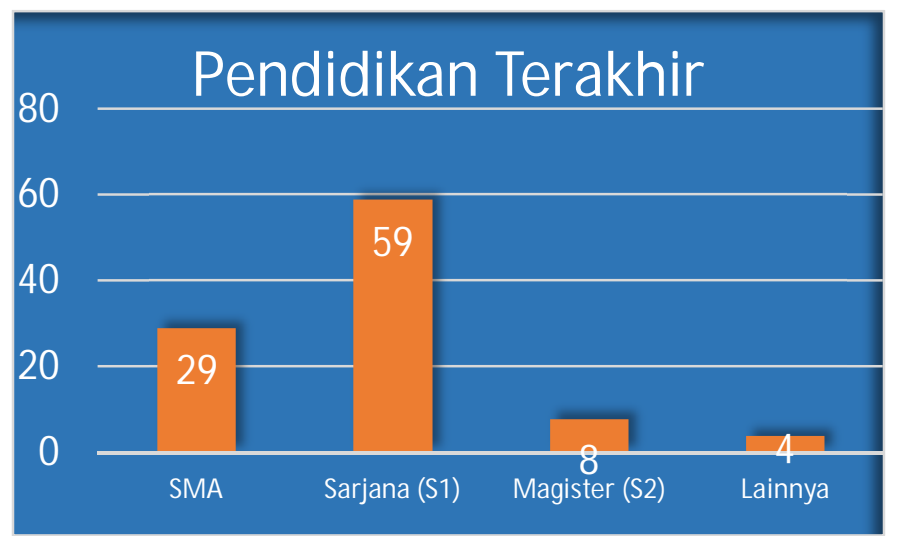

Gambar 5. Pendidikan Terakhir

Dari gambar 5 menunjukan bahwa data responden berdasarkan pendidikan terakhir paling banyak berasal dari sarjana (S1) berjumlah 59 orang dengan persentase 59\%, lalu dikuti dengan SMA sebanyak 29 orang dengan persentase 29\%, kemudian magister (S2) berjumlah 8 orang dengan persentase $8 \%$ dan lainnya sebanyak 4 orang dengan persentase 4\%. Gambar 6 adalah data responden berdasarkan pekerjaan.

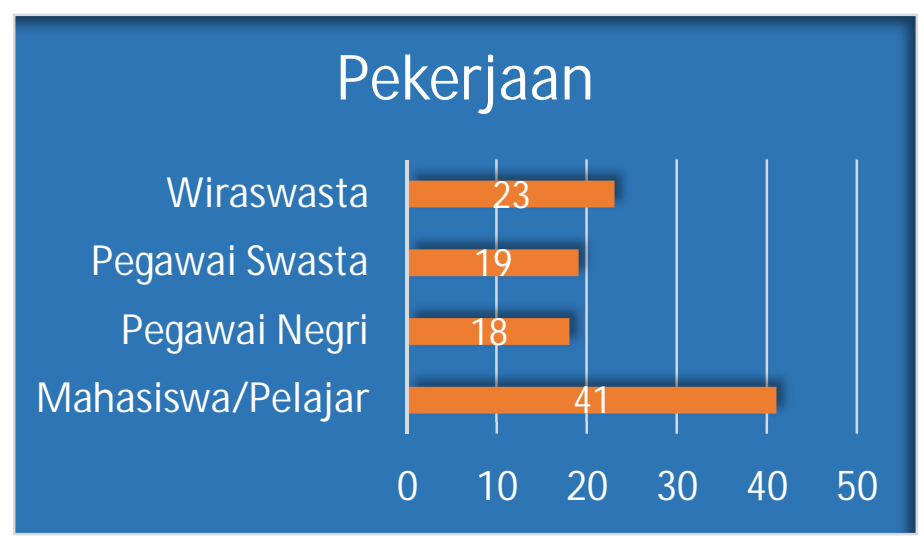

Gambar 6. Pekerjaan

Dari Gambar 6 menunjukan bahwa pekerjaan responden paling banyak berasal dari mahasiswa/pelajar berjumlah 41 orang dengan persentase $41 \%$, lalu diikuti dengan wiraswasta berjumlah 23 orang dengan persentase $23 \%$, kemudian pegawai swasta berjumlah 19 orang dengan persentase $19 \%$, terakhir pegawai negeri berjumlah 18 orang dengan $18 \%$. Gambar 7 adalah data responden berdasarkan jumlah transaksi.

\section{Jumlah Transaksi}

45

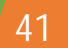

1 Kali 2-3 Kali $>3$ Kali

Gambar 7. Jumlah Transaksi 
Dari gambar 7 menunjukan bahwa jumlah transaksi yang pernah dilakukan mengunakan KAI Access yang pertama sebanyak lebih dari 3 kali transaksi berjumlah 45 orang dengan persentase $45 \%$, kemudian diikuti oleh 2 sampai 3 kali transaksi berjumlah 41 orang dengan persentase $41 \%$, dan yang bertransaksi 1 kali berjumlah 14 orang dengan persentase $14 \%$.

\subsection{Uji Validitas dan Reliabilitas}

Uji validitas pada penelitian ini untuk mengetahui seberapa baik instrumen digunakan untuk mengukur konsep yang seharusnya diukur, untuk menguji validitas konstruk yang dilakukan dengan cara mengorelasikan antara skor butir pertanyaan dengan skor totalnya. Hasil dari perhitungan uji validitas ditunjukan Tabel 2.

Tabel 2. Uji Validitas

\begin{tabular}{|c|c|c|c|c|}
\hline Indikator & rtabel & rhitung & Signifikan & Keterangan \\
\hline C1 & 0,195 & 0,617 & 0,000 & Valid \\
\hline C2 & 0,195 & 0,619 & 0,000 & Valid \\
\hline C3 & 0,195 & 0,650 & 0,000 & Valid \\
\hline C4 & 0,195 & 0,643 & 0,000 & Valid \\
\hline A1 & 0,195 & 0,650 & 0,000 & Valid \\
\hline A2 & 0,195 & 0,659 & 0,000 & Valid \\
\hline A3 & 0,195 & 0,754 & 0,000 & Valid \\
\hline A4 & 0,195 & 0,662 & 0,000 & Valid \\
\hline F1 & 0,195 & 0,629 & 0,000 & Valid \\
\hline F2 & 0,195 & 0,629 & 0,000 & Valid \\
\hline F3 & 0,195 & 0,544 & 0,000 & Valid \\
\hline F4 & 0,195 & 0,675 & 0,000 & Valid \\
\hline E1 & 0,195 & 0,611 & 0,000 & Valid \\
\hline E2 & 0,195 & 0,628 & 0,000 & Valid \\
\hline E3 & 0,195 & 0,650 & 0,000 & Valid \\
\hline E4 & 0,195 & 0,649 & 0,000 & Valid \\
\hline E5 & 0,195 & 0,681 & 0,000 & Valid \\
\hline T1 & 0,195 & 0,637 & 0,000 & Valid \\
\hline T2 & 0,195 & 0,619 & 0,000 & Valid \\
\hline T3 & 0,195 & 0,691 & 0,000 & Valid \\
\hline S1 & 0,195 & 0,714 & 0,000 & Valid \\
\hline S2 & 0,195 & 0,664 & 0,000 & Valid \\
\hline S3 & 0,195 & 0,616 & 0,000 & Valid \\
\hline
\end{tabular}

Dari hasil uji validitas variabel EUCS dengan menggunakan SPSS terhadap 100 responden dapat diambil kesimpulan bahwa semua pertanyaan kuesioners pada penelitian ini memiliki nilai rhitung $>$ rtabel dan nilai signifikansi $<0,05$. Sehingga semua pertanyaan kuesioner dapat digunakan dalam penelitian ini.

Reliabilitas berhubungan dengan tingkat ketepatan hasil pengukuran. Kuesioner dikatakan reliabel jika dapat memberikan hasil relative sama pada saat dilakukan pengukuran kembali pada objek yang berlainan pada waktu yang berbeda atau memberikan hasil yang tepat. Hasil uji reliabilitas dapat dilihat pada Tabel 3. 
Tabel 3. Uji Reliabilitas

\begin{tabular}{|c|c|c|c|}
\hline Variabel & Cronbach Alpha & Standar Reliabilitas & Keterangan \\
\hline Content & 0,743 & 0,6 & Reliabel \\
\hline Accuracy & 0,769 & 0,6 & Reliabel \\
\hline Format & 0,688 & 0,6 & Reliabel \\
\hline Ease Of Use & 0,754 & 0,6 & Reliabel \\
\hline Timeliness & 0,736 & 0,6 & Reliabel \\
\hline Satisfaction & 0,748 & 0,6 & Reliabel \\
\hline
\end{tabular}

Dari hasil uji reliabilitas semua variabel diperoleh nilai-nilai Cronbach Alpha dari semua variabel penelitian ini menunjukkan lebih besar dari nilai 0,6 maka demikian jawaban- jawaban responden dari variabel-variabel penelitian tersebut reliable, sehingga dapat digunakan untuk penelitian selanjutnya.

\subsection{Analisis Korelasi}

Analisis korelasi parsial dapat digunakan untuk mengetahui kekuatan hubungan antara korelasi kedua variabel dimana variabel lainnya yang dianggap berpengaruh dikendalikan atau dibuat tetap. Karena variabel yang diteliti adalah data interval maka teknik statistik yang digunakan adalah Pearson Correlation Product Moment. Tabel 4 adalah hasil analisis korelasi menggunakan SPSS.

Tabel 4. Analisis Korelasi

\begin{tabular}{|l|l|c|}
\hline \multicolumn{2}{|l|}{ Model } & Satsifaction \\
\hline Content & Pearson Corelation & 0,127 \\
& Signifikan & 0,184 \\
& $\mathrm{~N}$ & 100 \\
\hline Accuracy & Pearson Corelation & 0,657 \\
& Signifikan & 0,002 \\
& $\mathrm{~N}$ & 100 \\
\hline Format & Pearson Corelation & 0,683 \\
& Signifikan & 0,002 \\
& $\mathrm{~N}$ & 100 \\
\hline Ease Of Use & Pearson Corelation & 0,115 \\
& Signifikan & 0,256 \\
& $\mathrm{~N}$ & 100 \\
\hline Timeliness & Pearson Corelation & 0,708 \\
& Signifikan & 0,002 \\
& $\mathrm{~N}$ & 100 \\
\hline
\end{tabular}

Berdasarkan Tabel 4 hasil analisis korelasi diatas dapat disimpulkan sebagai berikut:

1. Berdasarkan hasil korelasi, diperoleh nilai $\mathrm{r}$ hitung content (X1) terhadap kepuasan pengguna (Y) sebesar 0,127, termasuk di interval 0,00-0,199 dengan tingkat hubungan lemah.

2. Berdasarkan hasil korelasi, diperoleh nilai $r$ hitung accuracy (X2) terhadap kepuasan pengguna (Y) sebesar 0,657, termasuk di interval 0,60-0,799 dengan tingkat hubungan kuat.

3. Berdasarkan hasil korelasi, diperoleh nilai $r$ hitung format (X3) terhadap kepuasan pengguna (Y) sebesar 0,683, termasuk di interval 0,60-0,799 dengan tingkat hubungan kuat. 
4. Berdasarkan hasil korelasi, diperoleh nilai $r$ hitung ease of use (X4) terhadap kepuasan pengguna (Y) sebesar 0,115, termasuk di interval 0,00-0,199 dengan tingkat hubungan lemah.

5. Berdasarkan hasil korelasi, diperoleh nilai $r$ hitung timeliness (X5) terhadap kepuasan pengguna (Y) sebesar 0,708, termasuk di interval 0,60-0,799 dengan tingkat hubungan kuat.

\subsection{Analisis Regresi Linier Berganda}

Analisis regresi berganda dalam penelitian ini bertujuan untuk mengetahui bagaimana pengaruh variabel independen terhadap dependen. Tabel 5 adalah hasil analisis regresi linier berganda.

Tabel 5 Analisis Regresi Linier Berganda

\begin{tabular}{|c|c|}
\hline Model & B \\
\hline 1(Constant) & 5,519 \\
\hline Content & 0,010 \\
\hline Accuracy & 0,204 \\
\hline Format & 0236 \\
\hline Ease of Use & 0,008 \\
\hline Timeliness & 0,297 \\
\hline
\end{tabular}

berikut:

Berdasarkan hasil analisis Tabel 5 diatas dijelaskan melalui model regresi sebagai

Dari persamaan regresi tersebut dapat dijelaskan sebagai berikut:

1. Konstanta $=5,519$. Artinya jika variabel content, accuracy, format, ease of use, dan timeliness diangap sama dengan nol, maka variabel satisfaction mempunyai nilai 5,519.

2. Koefisien content $=0,010$ Artinya jika variabel content mengalami kenaikan sebesar 1 satuan sedangkan variabel lain dianggap konstan, maka variabel dependen yaitu satisfaction akan mengalami kenaikan sebesar 0,010 .

3. Koefisien accuracy $=0,204$. Artinya jika variabel accuracy mengalami kenaikan sebesar 1 satuan sedangkan variabel lain dianggap konstan, maka variabel dependen yaitu satisfaction akan mengalami kenaikan sebesar 0,204.

4. Koefisien format $=0,236$. Artinya jika variabel format mengalami kenaikan sebesar 1 satuan sedangkan variabel lain dianggap konstan, maka variabel dependen yaitu satisfaction akan mengalami kenaikan sebesar 0,236.

5. Koefisien ease of use $=0,008$. Artinya jika variabel ease of use mengalami kenaikan sebesar 1 satuan sedangkan variabel lain dianggap konstan, maka variabel dependen yaitu satisfaction akan mengalami kenaikan sebesar 0,008.

6. Koefisien timeliness $=0,297$. Artinya jika variabel timeliness mengalami kenaikan sebesar 1 satuan sedangkan variabel lain dianggap konstan, maka variabel dependen yaitu satisfaction akan mengalami kenaikan sebesar 0,297.

\subsection{Uji Hipotesis}

\subsubsection{Uji t}

Uji t ini dilakukan untuk menguji tingkat signifikasi pengaruh variabel independen terhadap varibel dependen secara parsial. Tingkat signifikansi yang digunakan sebesar 5\%. Jika tingkat signifikan $<0,05$ dan niali $\mathrm{t}$ hitung $>\mathrm{t}$ tabel maka variabel independen secara individual berpengaruh terhadap variabel dependen. Dalam penelitian ini mencari nilai t tabel $=\mathrm{t}(\alpha /$ $2 ; \mathrm{n}-\mathrm{k}-1)=\mathrm{t}(0,025 ; 94)=1,985$. Tabel 6 adalah hasil uji $\mathrm{t}$ dari hasil pengolahan data menggunakan SPSS. 
Tabel 6 Uji t

\begin{tabular}{|c|c|c|}
\hline Model & $\mathbf{t}$ & Signifikan \\
\hline 1(Constant) & 3,193 & 0,002 \\
\hline Content & 1,235 & 0,220 \\
\hline Accuracy & 2,148 & 0,008 \\
\hline Format & 2,829 & 0,006 \\
\hline Ease of Use & 0,141 & 0,888 \\
\hline Timeliness & 2,923 & 0,004 \\
\hline
\end{tabular}

Hasil pengujian secara parsial adalah sebagai berikut:

1. Diketahui nilai signifikansi untuk pengaruh variabel content terhadap variabel satisfaction adalah sebesar 0,220 >0,05 (signifikansi 5\%) dan nilai t hitung 1,235 < t tabel 1,985, sehingga dapat disimpulkan bahwa $\mathrm{H} 1$ yaitu content tidak berpengaruh terhadap satisfaction.

2. Diketahui nilai signifikansi untuk pengaruh variabel accuracy terhadap variabel satisfaction adalah sebesar 0,008 $<0,05$ (signifikansi 5\%) dan nilai t hitung 2,148 $>\mathrm{t}$ tabel 1,985, sehingga dapat disimpulkan bahwa H2 yaitu accuracy berpengaruh terhadap satisfaction.

3. Diketahui nilai signifikansi untuk pengaruh variabel format terhadap variabel satisfaction adalah sebesar $0,006<0,05$ (signifikansi 5\%) dan nilai t hitung 2,829 > t tabel 1,985, sehingga dapat disimpulkan bahwa $\mathrm{H} 3$ yaitu format berpengaruh terhadap satisfaction.

4. Diketahui nilai signifikansi untuk pengaruh variabel ease of use terhadap variabel satisfaction adalah sebesar 0,888 $>0,05$ (signifikansi 5\%) dan nilai t hitung 0,141 $<\mathrm{t}$ tabel 1,985, sehingga dapat disimpulkan bahwa $\mathrm{H} 4$ yaitu ease of use tidak berpengaruh terhadap satisfaction

5. Diketahui nilai signifikansi untuk pengaruh variabel timeliness terhadap variabel satisfaction adalah sebesar 0,004 $<0,05$ (signifikansi 5\%) dan nilai thitung 2,923 $>\mathrm{t}$ tabel 1,985, sehingga dapat disimpulkan bahwa H5 yaitu timeliness berpengaruh terhadap satisfaction.

\subsubsection{Uji F}

Uji F ini dilakukan untuk menunjukan apakah variabel independen yang dimasukkan dalam model mempunyai pengaruh secara bersama-sama terhadap variabel dependen. Pengujian dilakukan dengan tingkat signifikansi $5 \%$ atau 0,05 . Dalam penelitian ini diperoleh nilai $\mathrm{F}$ tabel dengan cara sebagai berikut $\mathrm{F}$ tabel $=\mathrm{F}(\mathrm{k} ; \mathrm{n}-\mathrm{k})=\mathrm{F}(5 ; 95)=2,31$. Didapatkannya hasil analisis uji F seperti di Tabel 7 berikut:

Tabel 7 Uji F

\begin{tabular}{|c|c|c|c|c|c|c|}
\hline \multicolumn{2}{|c|}{ Model } & $\begin{array}{c}\text { Sum of } \\
\text { Squares }\end{array}$ & df & $\begin{array}{c}\text { Mean } \\
\text { Square }\end{array}$ & F & Sig. \\
\hline \multirow{2}{*}{1} & Regression & 1019,484 & 5 & 203,897 & 46,862 & $0,002^{\mathrm{b}}$ \\
\cline { 2 - 7 } & Residual & 389,426 & 94 & 4,351 & & \\
\cline { 2 - 7 } & Total & 1408,910 & 99 & & & \\
\hline
\end{tabular}

Berdasarkan Tabel 7 hasil uji $\mathrm{F}$ di atas dapat diperoleh nilai signifikansi untuk pengaruh variabel content, accuracy, format, ease of use, dan timeliness terhadap satisfaction sebesar 0,002 kurang dari 0,05 dan nilai $F$ hitung 46,862 lebih besar dari $F$ tabel 2,31, sehingga dapat disimpulkan bahwa terdapat pengaruh variabel $\mathrm{X}$ terhadap variabel $\mathrm{Y}$. 


\subsection{Uji Koefesien Determinan $\left(R^{2}\right)$}

Nilai koefesien determinasi ditunjukan oleh nilai $\mathrm{R}^{2}$ dari model regresi digunakan untuk mengetahui besarnya variabilitas variabel dependen yang dapat dijelaskan oleh variabel-variabel bebasnya. Tabel 8 adalah hasil analisis koefisien determinan.

Tabel 8 Hasil Uji Koefisien Determinan

\begin{tabular}{|l|r|r|r|r|}
\hline Model & R & R Square & $\begin{array}{c}\text { Adjusted R } \\
\text { Square }\end{array}$ & $\begin{array}{c}\text { Std. Error of } \\
\text { the Estimate }\end{array}$ \\
\hline 1 & $0,723^{\mathrm{a}}$ & 0,679 & 0,635 & 1,975 \\
\hline
\end{tabular}

Berdasarkan Tabel 8 diatas diketahui bahwa nilai $\mathrm{R}^{2}$ sebesar 0,679 hal ini mengandung arti variabilitas variabel satisfaction yang dapat dijelaskan oleh variabel content, accuracy, format, ease of use dan timeliness sebesar $67,9 \%$. Sedangkan sisanya 32,5\% dijelaskan oleh variabel-variabel independen yang tidak disertakan dalam penelitian ini.

\subsection{Pembahasan}

Pembahasan dari hasil pengujian hipotesis menggunakan uji t untuk uji parsial masingmasing variabel independent terhadap variabel dependent, dapat dijelaskan sebagai berikut:

1. Pengaruh Content (X1) terhadap kepuasan pengguna (Y)

Berdasarkan hasil uji t, didapatkan nilai t hitung sebesar 1,235 kurang dari t tabel 1,985 dan tingkat signifikansi sebesar 0,220 lebih besar dari 0,05. Artinya dapat disimpulkan bahwa tidak ada pengaruh signifikan antara variabel content terhadap satisfaction. Menurut persepsi responden secara umum menganggap isi informasi pada aplikasi KAI Access tidak sesuai harapan pengguna, disebabkan karena terdapat menu yang ditampilkan di aplikasi tetapi pengguna diharuskan mendowload aplikasi yang berbeda jika ingin menggunakan menu tersebut dan informasi yang dibutuhkan pengguna masih kurang lengkap.

2. Pengaruh Accuracy (X2) terhadap kepuasan pengguna (Y)

Berdasarkan hasil uji t, didapatkan nilai t hitung sebesar 2,148 lebih besar dari t tabel 1,985 dan tingkat signifikansi sebesar 0,009 kurang dari 0,05. Artinya dapat disimpulkan bahwa ada pengaruh signifikan antara variabel accuracy terhadap variabel satisfaction. Menurut persepsi responden secara umum menganggap keakuratan informasi pada aplikasi KAI Access sudah memuaskan penggunanya karena minimnya kesalahan ketika aplikasi menerima inputan, kemudian mengelolahnya menjadi suatu informasi.

3. Pengaruh Format (X3) terhadap kepuasan pengguna (Y)

Berdasarkan hasil uji t, didapatkan nilai t hitung sebesar 2,829 lebih besar dari t tabel 1,985 dan tingkat signifikansi sebesar 0,006 kurang dari 0,05. Artinya dapat disimpulkan bahwa ada pengaruh signifikan antara variabel format terhadap variabel satisfaction. Menurut persepsi responden secara umum menggangap tampilan pada aplikasi KAI Access sudah sesuai dengan harapan dan keinginan pengguna, jadi pengguna merasa puas dengan tampilan aplikasi.

4. Pengaruh Ease of Use (X4) terhadap kepuasan pengguna (Y)

Berdasarkan hasil uji t, didapatkan nilai t hitung sebesar 0,141 kurang dari t tabel 1,985 dan tingkat signifikansi sebesar 0,006 lebih besar dari 0,05. Artinya dapat disimpulkan bahwa tidak ada pengaruh signifikan antara variabel ease of use dengan variabel satisfaction. Menurut persepsi responden secara umum menganggap kemudahan penggunaan pada aplikasi KAI Access tidak sesuai harapan pengguna, dikarenakan KAI Access belum terdapat bantuan untuk pengguna baru dalam mengaplikasikan sistem.

5. $\quad$ Pengaruh Timeliness (X5) terhadap kepuasan pengguna (Y)

Berdasarkan hasil uji t, didapatkan nilai t hitung sebesar 2,923 lebih besar dari t tabel 1,985 dan tingkat signifikansi sebesar 0,004 kurang dari 0,05. Artinya dapat disimpulkan bahwa ada pengaruh signifikan antara variabel timeliness dengan variabel satisfaction. Menurut 
persepsi responden secara umum menganggap kecepatan waktu aplikasi KAI Access dalam mencari data dan informasi yang dibutuhkan oleh penggunanya sudah memuaskan

6. Kepuasan Pengguna Terhadap KAI Access menggunakan Model EUCS

Berdasarkan hasil yang didapatkan melalui uji statistik yang dilakukan menggunakan SPSS dengan melakukan uji hipotesis yaitu uji $\mathrm{F}$, apakah variabel content, accuracy, format, ease of use, dan timeliness mempunyai pengaruh secara bersama-sama terhadap variabel dependen satisfaction, didapatkan hasil yaitu variabel content, accuracy, format, ease of use, dan timeliness, berpengaruh terhadap kepuasan pengguna KAI Access.

\section{KESIMPULAN}

Berdasarkan hasil analisis data yang sudah dilakukan, dapat disimpulkan bahwa dari lima hipotesis yang dilakukan yaitu variabel content (X1), accuracy (X2), variabel format (X3), ease of use (X4), dan timeliness (X5) secara simultan memberikan pengaruh terhadap variabel satisfaction (Y) sebesar 0,679 atau 67,9\% artinya dari 100 responden menghasilkan 68 responden yang merasa puas dengan aplikasi KAI Access. Berdasarkan uji t diketahui ada 2 variabel yang tidak berpengaruh yaitu variabel content dan ease of use dan 3 variabel yang berpengaruh terhadap satisfaction (Y).

Pada kelima variabel $\mathrm{X}$ diketahui para pengguna tidak puas terhadap content dan ease of use yang dihasilkan aplikasi KAI Access untuk itu perlu peningkatan kualitas dan kelengkapan yang ada pada sisi content dan ease of use agar lebih bermanfaat dan meningkatkan kepuasan pengguna nya.

\section{SARAN}

Berdasarkan hasil penelitian yang sudah diperoleh, dapat ditambahkan saran untuk penelitian selanjutnya, yaitu:

1. Diharapkan dapat menggunakan metode yang berbeda untuk membandingkan dengan penelitian yang sudah dilakukan sebelumnya, atau menggunakan metode yang sama dengan kasus yang berbeda dan dengan jumlah populasi yang lebih besar.

2. Saran yang dapat diberikan kepada perusahaan KAI adalah perusahaan dapat meningkatkan dan mengoptimalkan lagi aplikasi KAI Access untuk memberikan layanan yang mengutamakan kepuasan pengguna sehingga dapat terus mempertahankan loyalitas pengguna KAI Access.

\section{DAFTAR PUSTAKA}

[1] K. Hurit, 2017. Transportasi Secara Umum. Erlangga, Jakarta.

[2] A. Suwondo and F. I. Marjan, 2017, "Analisis Pengaruh E-Kepuasan Pelanggan Terhadap E-Loyalitas Pelanggan KAI ACCESS Berdasarkan E-Servequal Pada PT Kereta Api Indonesia (Persero) Daop IV Semarang," in Sentrinov (Seminar Nasional Terapan Riset Inovatif), Vol. 3, pp. 338-360.

[3] A. R. Darwi and E. Efrizon, 2019, “Analisis Kepuasan Pengguna E-Learning Sebagai Pendukung Aktivitas Pembelajaran Menggunakan Metode EUCS," Voteteknika (Vocational Teknik Elektronika dan Informatika, Vol. 7, No. 1, p. 25, doi: 10.24036/voteteknika.v7i1.103639. 
[4] W. J. Doll and G. Torkzadeh, 1988, "The Measurement of End-User Computing Satisfaction End-User Satisfaction The Measurement of End-User Computing Satisfaction," Source MIS Q., Vol. 1213512, No. 2, pp. 259-274, [Online]. Available: http://www.jstor.org/stable/248851\%0Ahttp://www.jstor.org/page/info/about/policies/ter ms.jsp\%0Ahttp://www.jstor.org.

[5] N. P. Ayu Wangi Diantini, S. Sukidin, and W. Hartanto, 2019, “Efektivitas Penerapan Mobile Application 'Kai Access' Oleh Konsumen di PT. Kereta Api Indonesia Persero Daerah Operasi 9 Stasiun Jember," Jurna Pendidikan Ekonomi Jurnal Ilmu Ilmu Pendidikan, Ilmu Ekonomi dan Ilmu Sosial, Vol. 13, No. 2, p. 132, doi: 10.19184/jpe.v13i2.11477.

[6] Y. Sutanto, 2015, "Analisis Kepuasan Pengguna Website Manajemen Informatika Dengan Metode EUCS Berbasis CMS,” Informatika, Vol. 2, No. 1, pp. 1-18.

[7] D. Novita and F. Helena, 2021, “Analisis Kepuasan Pengguna Aplikasi Traveloka Menggunakan Metode Technology Acceptance Model (TAM) dan End-User Computing Satisfaction (EUCS)," Jurnal Teknologi Sistem Informasi, Vol. 2, No. 1, pp. $22-37$.

[8] A. Suharsimi, 2010, Prosedur Penelitian Suatu Pendekatan Praktik. PT Rineka Cipta, Jakarta.

[9] W. W. Chin and M. K. O. Lee, 2000, "A Proposed Model and Measurement Instrument For The Formation of Is Satisfaction: The Case Of End-User Computing Satisfaction,"

[10] A. Fitriansyah and I. Harris, 2018, "Pengukuran Kepuasan Pengguna Situs Web Dengan Metode End User Computing Satisfaction (EUCS)," Query Jurnal Sistem Informasi, Vol. 2, No. 1, pp. 1-8, [Online]. Available: http://jurnal.uinsu.ac.id/index.php/query/article/view/1552.

[11] A. N. Rahmi, Supriatin, and D. Prabowo, 2019. "Evaluasi Kepuasan Pengguna Aplikasi AMIKOM ONE Menggunakan Metode EUCS,” INFOS Jurnal, Vol. 2, No. 1, pp. 67-73,

[12] A. Saputra and D. Kurniadi, 2019, "Analisis Kepuasan Pengguna Sistem Informasi ECampus di IAIN Bukittinggi Menggunakan Metode Eucs," Jurnal Vokasional Teknik Elektronika dan Informatika, Vol. 7, No. 3, pp. 58-66,

[13] D. Novita and D. S. Ningsih, 2020, “Analisis Pengaruh Implementasi E-Learning Vilep di Poltekkes Kemenkes Palembang Dengan Pendekatan EUCS," JATISI (Jurnal Teknik Informatika dan Sistem Informasi), Vol. 7, No. 1, pp. 29-41, doi: 10.35957/jatisi.v7i1.290. 